\title{
Tissue sampling using a submucosal tunnelling technique for indefinite gastric amyloidosis
}

Hideki Kobara MD PhD, Makoto Oryu MD PhD, Hirohito Mori MD PhD, Shintaro Fujihara MD, Noriko Nishiyama MD, Yasuhiro Goda MD, Taiga Chiyo MD, Tae Matsunaga MD, Maki Ayaki MD, Tatsuo Yachida MD,

Toshiaki Nakatsu MD PhD, Tsutomu Masaki MD PhD

\section{CASE PRESENTATION}

An 80-year-old man with epigastric discomfort underwent upper gastrointestinal endoscopy. Endoscopic findings revealed a granular, elevated lesion (diameter $20 \mathrm{~mm}$ ) localized to the posterior wall of the prepyloric ring (Figure 1). Abdominal ultrasonography revealed a hypoechoic mass localized to the submucosa. Although biopsy samples were acquired from the epithelium of this lesion to differentiate among gastric epithelial neoplasms, including carcinoma, lymphoma and other diseases, these samples could not histologically diagnose the lesion. After obtaining informed consent, a submucosal tunnelling procedure was selected, considering the antral stricture after endoscopic mucosal resection. We have developed a submucosal tunnelling technique for sampling submucosal tumours, which can visualize tumour surfaces and obtain tissue samples under direct visualization $(1,2)$. After marking the normal mucosa around the lesion with $10 \mathrm{~mm}$ margins, a small incision was made to create a $10 \mathrm{~mm}$ opening flap (Figure 2). The submucosa was dissected toward the lesion, creating a submucosal tunnel. A whitish mass was visually identified in the submucosal tunnel, and several tissue samples were obtained using biopsy forceps (Radial Jaw 4 Standard Capacity, Boston Scientific, Japan) (Figure 3). The opening flap was completely closed by hemoclips (HX-610-135; Olympus, Japan) to prevent delayed complications. There were no complications associated with this procedure. Histological examination using Congo red staining was positive for amyloidal protein and exhibited green birefringence under polarized light microscopy. A diagnosis of gastric amyloid was made, and the patient was systemically examined, resulting in a lightchain fragment type of localized gastric amyloidosis.

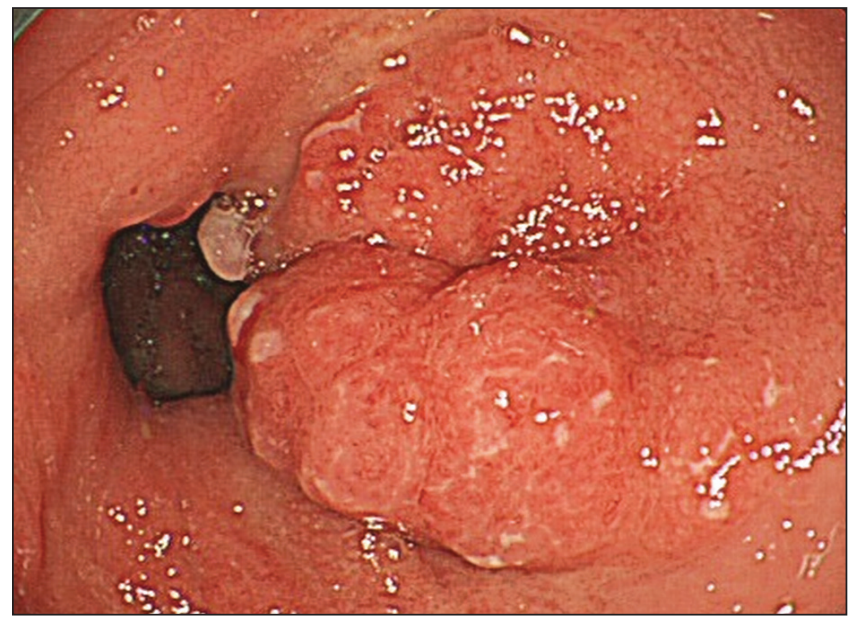

Figure 1) Endoscopic findings showing a granular-elevated lesion (20 mm diameter) localized to the posterior wall of the prepyloric ring

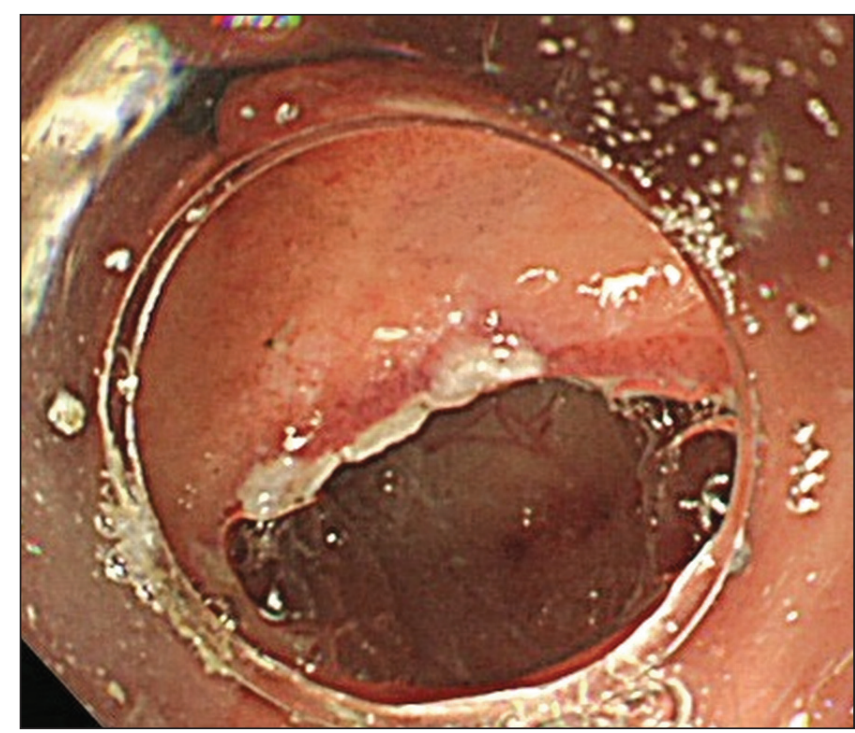

Figure 2) Endoscopic view showing a $10 \mathrm{~mm}$ opening flap created after marking the antral normal mucosa around the lesion with $10 \mathrm{~mm}$ margins

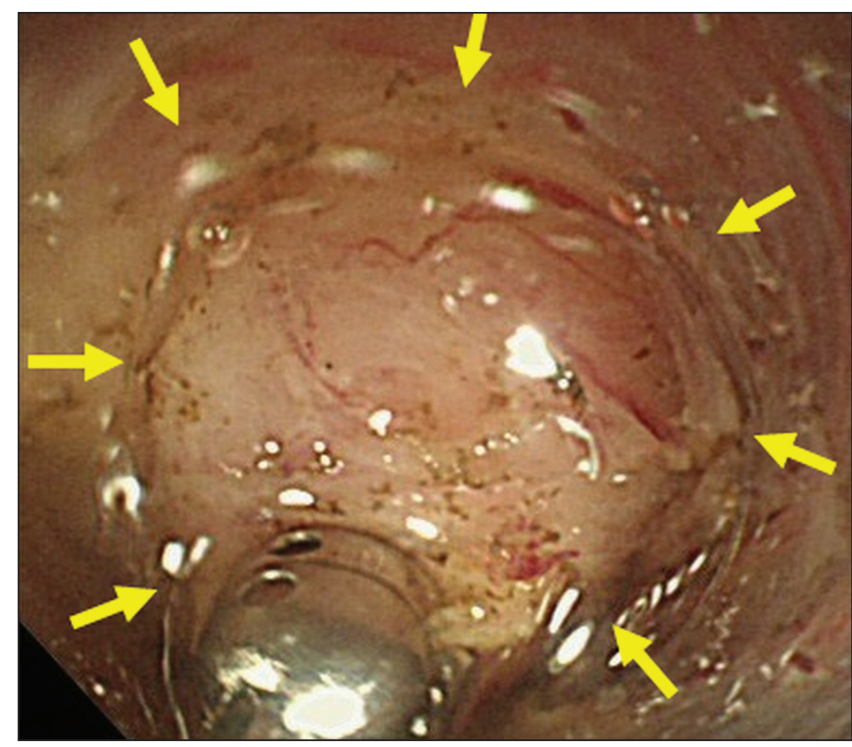

Figure 3) Endoscopic findings showing a whitish mass (arrows) visually identified in the dissected submucosal tunnel toward the lesion. Tissue samples from the mass were obtained using biopsy forceps

Department of Gastroenterology and Neurology, Faculty of Medicine, Kagawa University, Kagawa, Japan

Correspondence: Dr Hideki Kobara, Department of Gastroenterology and Neurology, Faculty of Medicine, Kagawa University, 1750-1 Ikenobe,

Miki, Kita, Kagawa 761-0793, Japan. Telephone 81-87-891-2156, fax 81-87-891-2158, e-mail kobara@med.kagawa-u.ac.jp

Received for publication December 31, 2014. Accepted January 12, 2015 


\section{DISCUSSION}

Amyloidosis primarily demonstrates systemic involvement of multiple tissues and organs; however, an amyloidal deposit localized to the stomach is highly unusual.

Histological confirmation of gastric amyloidosis using biopsy specimens appears to be occasionally difficult because of its infiltration of the submucosa, and the diagnosis of amyloidosis has been finalized in some cases only after invasive surgical resection (3). Recently, endoscopic mucosal resection has been used to obtain a larger resected specimen compared with a biopsy specimen (4). However, the method has some risks for delayed complications such as bleeding and stricture. The sampling method we developed, involving submucosal endoscopy with a mucosal flap (5), takes advantage of acquiring proper specimens under direct visualization, identifying the tumour itself and preventing adverse events owing to a safety mucosal flap. Accordingly, this novel method may be an alternative for acquiring adequate tissue samples of indefinite subepithelial lesions, leading to accurate therapeutic planning.
DISCLOSURES: The authors have no financial disclosures or conflicts of interest to declare.

\section{REFERENCES}

1. Kobara H, Mori H, Masaki T, et al. Bloc biopsy by using submucosal endoscopy with a mucosal flap method for gastric subepithelial tumor tissue sampling (with video). Gastrointest Endosc 2013;77:141-5.

2. Kobara H, Mori H, Oryu M, et al. Endoscopic visualized features of gastric submucosal tumors on submucosal endoscopy. Endoscopy 2014;46:E660.

3. Nfoussi H, Chelly I, Zitouna M, et al. Pseudo tumoral gastric amyloidosis: About a rare case report. Tunis Med 2010;88:670-3.

4. Kamata T, Suzuki H, Oda I, et al. Localized gastric amyloidosis differentiated histologically from scirrhous gastric cancer using endoscopic mucosal resection: A case report. J Med Case Rep 2012;6:231.

5. Sumiyama K, Gostout CJ, Rajan E, et al. Submucosal endoscopy with mucosal flap safety valve. Gastrointest Endosc 2007;65:688-94.

The Canadian Journal of Gastroenterology $\mathcal{E}$ Hepatology is considering a limited number of submissions for IMAGE OF THE MONTH. These are based on endoscopic, histological, radiological and/or patient images, which must be anonymous with no identifying features visible. The patient must consent to publication and the consent must be submitted with the manuscript. All manuscripts should be practical and relevant to clinical practice, and not simply a case report of an esoteric condition. The text should be brief, structured as CASE PRESENTATION and DISCUSSION, and not more than 700 words in length. A maximum of three images can be submitted and the number of references should not exceed five. The submission may be edited by our editorial team. 


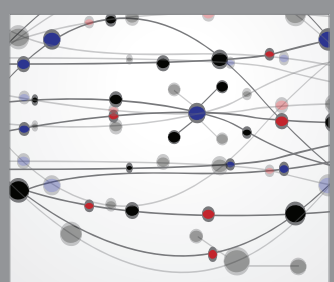

The Scientific World Journal
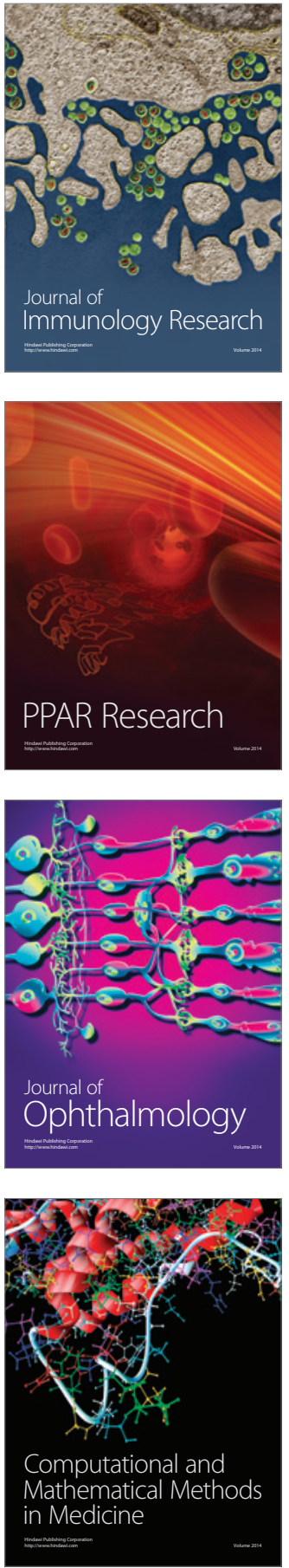

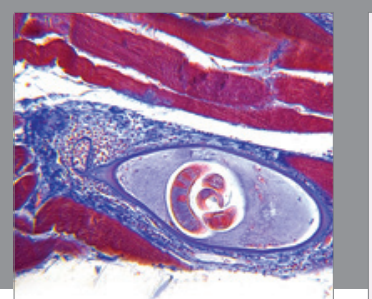

Gastroenterology Research and Practice

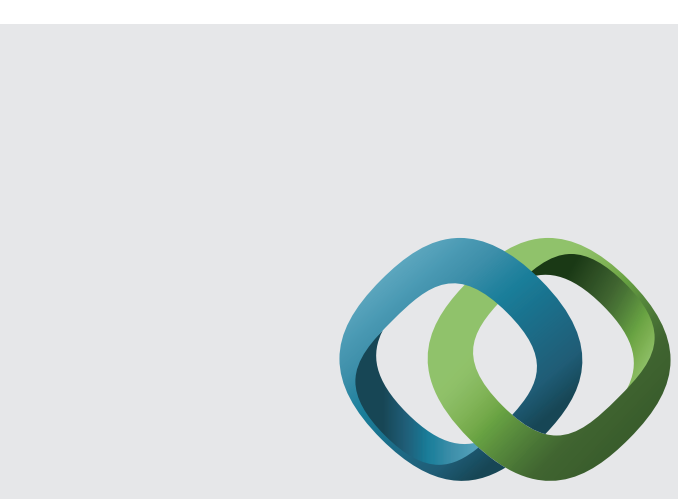

\section{Hindawi}

Submit your manuscripts at

http://www.hindawi.com
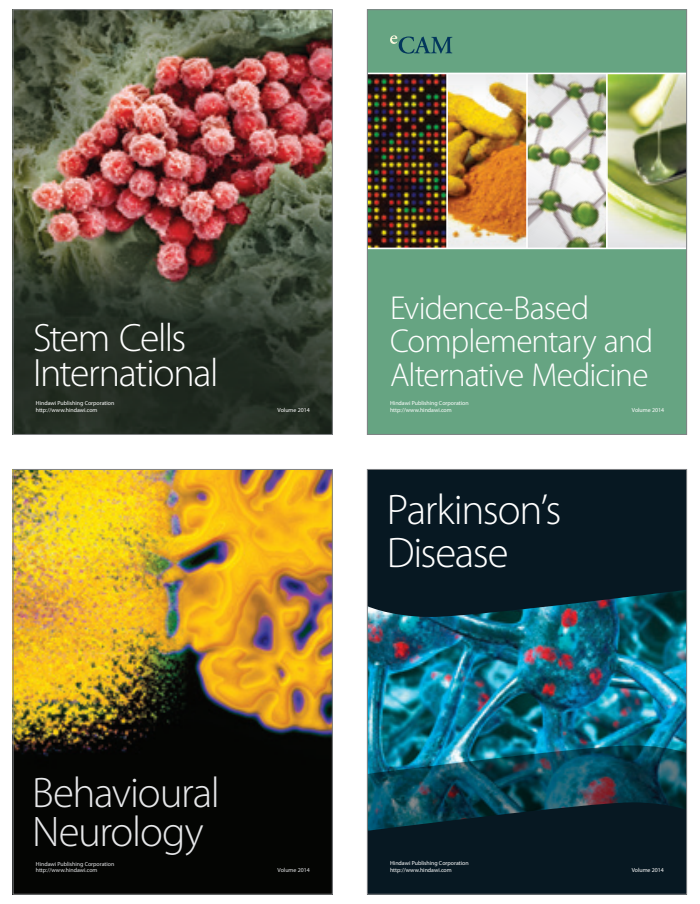
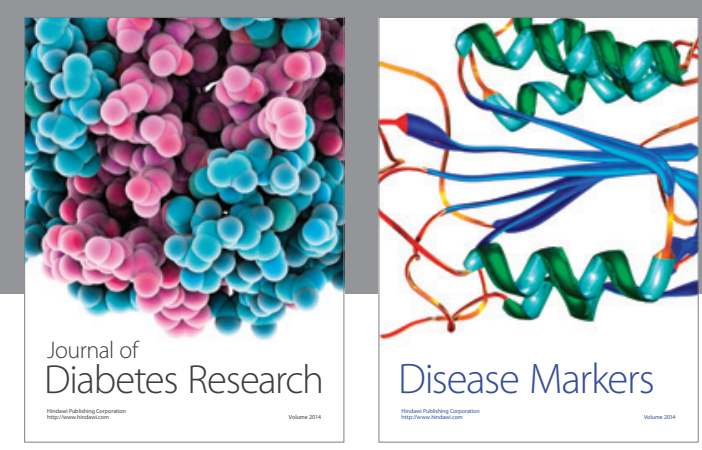

Disease Markers
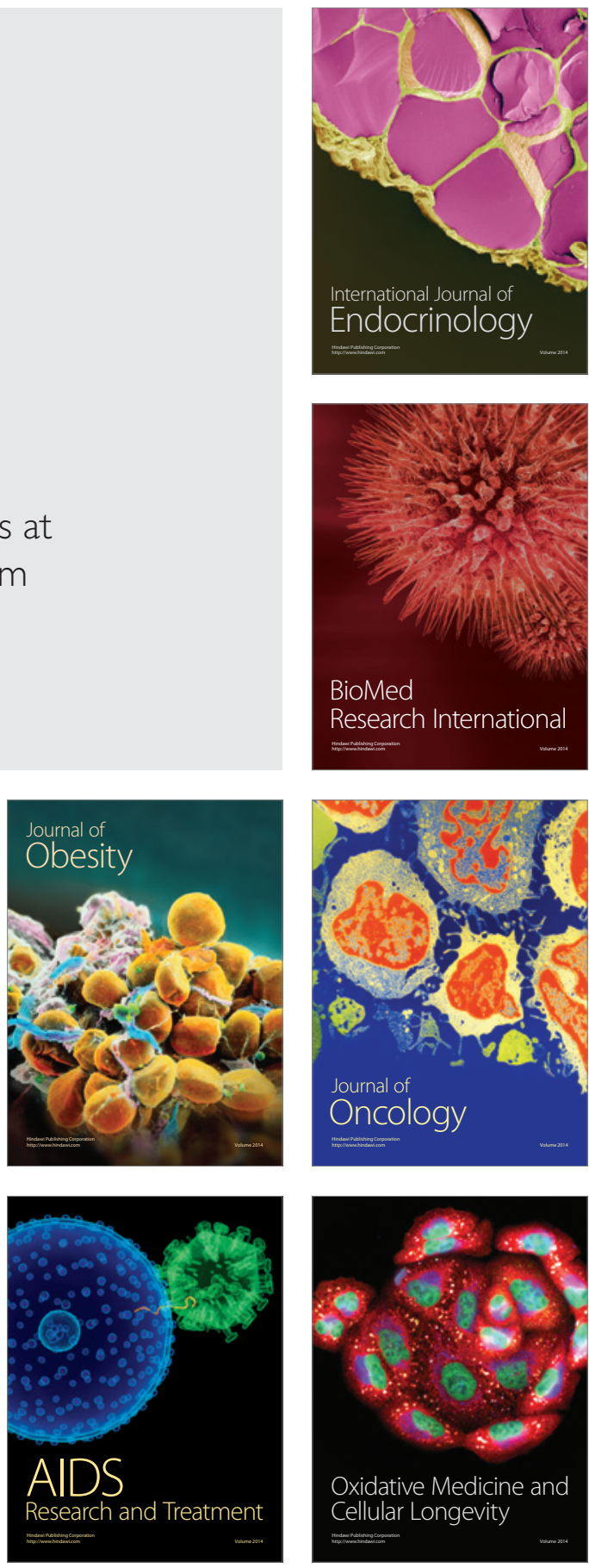